\title{
¿Optimizas las formas de pago en tu empresa?
}

\author{
Por Paul Granados \\ Coordinador de la carrera de Contaduría Pública UCA \\ Master en Finanzas y Master en Dirección de Empresas.
}

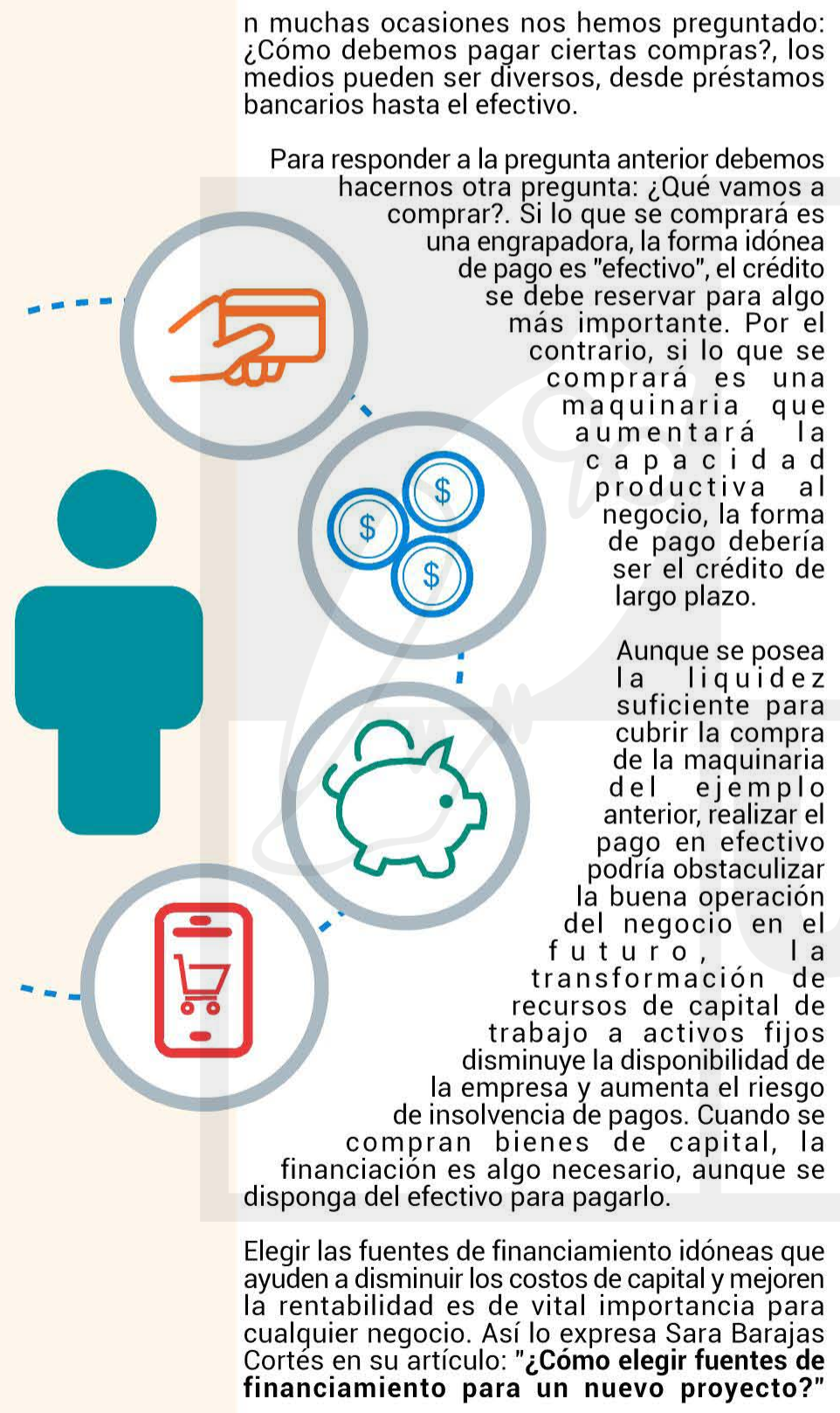

Al referirse a fuentes de financiamiento se debe tener claro que incluye tanto fondos propios como ajenos.

Los fondos propios se componen de: capital social, reservas y resultado. Este tipo de financiamiento no es deducible del impuesto sobre la renta, pero tampoco impacta los resultados por carga financiera correspondiente al pago de intereses.

Cuando los fondos propios no son suficientes, aparece la financiación ajena: fuente de fondos aportados por personas o entidades, que no son accionistas del negocio (proveedores, instituciones financieras, etc.). Este tipo de financiamiento tiene la prerrogativa de ser deducible fiscalmente.

Para el caso de las PYMES en muchas ocasiones se ven forzadas a recurrir a financiación propia (autofinanciación), esto debido a la falta de información contable y garantías que puedan ofrecer, así lo expresa la CEPAL en su informe: "Eliminando barreras: El financiamiento a las PYMES en América Latina". Cuando las PYMES logran formalizarse y ganar credibilidad en el mercado crediticio, lo usual es que recurran al crédito bancario a corto o mediano plazo, sin tomar en cuenta el bien que se adquirirá. En muchos casos este fondeo no es el más adecuado para las inversiones a realizar; aquí es donde entra a perspectiva la regla de oro: "NO financiar recursos permanentes con deudas altamente exigibles".

Atendiendo a la regla anterior, tres recomendaciones de pago por tipo de compra:

I. Compras de montos pequeños:

Los montos pequeños se debe optar por el pago de contado, un nuevo estudio realizado por Urban Institute y D2D Fund refuerza la idea de pagar las compras pequeñas con efectivo. Este estudio propone un punto medio: utilizar efectivo para cualquier pago inferior a los \$20.00, así se evita el endeudamiento innecesario. 
II. Compras de activo corrientes:

Para esto es trascendental analizar el período de realización de los activos; los saldos en cuentas bancarias no necesita ningún tipo de financiación. Por otra parte, los activos corrientes realizables: inventarios y créditos a cliente, por lo general producen necesidades de financiamiento (propio o ajeno) para el negocio. Para financiar los activos corrientes, es habitual que las empresas utilicen créditos de corto plazo: lineas de crédito rotativas, sobregiros bancarios, factorajes, entre otros. Un activo para ostentar la categoría de "corriente" debe convertirse en disponible en menos de un año, mientas que un pasivo para clasificarse de "corto plazo" debe tener una exigencia de pago menor a un año.

\section{Compras de activos no corrientes:}

Los terrenos, edificaciones, vehículos, mobiliario, en general, compras de bienes de capital con valores elevados se debe preferir la financiación de largo plazo. Dilatar las cuotas en el tiempo ayudará a una sana operación del negocio, aún cuando esta decisión conlleve el pago de más intereses.

El origen y destino del financiamiento es un elemento fundamental para el desarrollo económico de las empresas. Buscar la mejor estrategia de financiación para cada etapa del negocio puede ser el éxito o fracaso del negocio.

¿Cómo pagar? NO hay recetas mágicas, en función de las necesidades concretas de las empresas se debes evaluar lo más conveniente, analizar el ciclo operativo, así como, las necesidades de bienes de capital. Esto permitirá la sostenibilidad del negocio en el largo plazo. Si quiere que la empresa funcione sin interrupciones, recuerda la regla de oro: "NO financiar recursos permanentes con deudas altamente exigibles".

Bibliografía consultada

Sara Barajas Cortés. (2016).

"¿Cómo elegir fuentes de financiamiento

para un nuevo proyecto?" México: Forbes

Urban Institute \& D2D Fund (2016)

"An Evaluation of the Impacts

of Two "Rules of Thumb" for Credit Card Revolvers"

Estados Unidos: Urban Institute

NU CEPAL. (2011). "Eliminando barreras: el financiamiento a las PYMES en América Latina" Chile: CEPAL

\section{Créditos Personales}

Por Paul Granados

Coordinador de la carrera de Contaduría Pública UCA

Master en Finanzas y Master en Dirección de

Empresas.

Es posible que a lo largo del día tengamos que dividir el tiempo en: manejar al equipo de trabajo, conseguir ventas, mejorar el servicio al cliente, promover el negocio, crear nuevos productos o servicios, etc. Lo último que queremos es añadir más carga de trabajo a nuestro día como el cuidado de las finanzas personales. No obstante, si NO se tienen las finanzas del hogar en orden, sólo se está agregando más caos y estrés a la vida.

El manejo de las finanzas personales puede ser un camino complejo de recorrer. Equilibrar los ingresos y los egresos es fundamental para una buena salud financiera. Los imprevistos como: desperfectos en el hogar o del automóvil, enfermedades de algún miembro de la familia afectan cualquier presupuesto familiar, razón que podría llevar a la solicitud de créditos que no pasen por el tamiz de un análisis previo.

Si llega el momento de solicitar un crédito, se debe considerar aspectos que permitan tener un mejor control de las finanzas personales y aprovechar estos a beneficio propio. A continuación, se ofrecen cuatro recomendaciones que se deben tomar en cuenta antes al solicitar un crédito:

1. ¿Es absolutamente necesario solicitar el crédito? El crédito debe satisfacer una necesidad y no un deseo.

2. Analizar las diferentes alternativas de créditos: Antes de firmar con una institución financiera por el fácil acceso que ofrece, es importante estudiar las diferentes opciones de créditos disponibles en el mercado, así como, los costos y plazos contractuales. Se debe elegir la opción que mejor se adapte a la necesidad y estilo de vida. El crédito más rápido no necesariamente es el mejor.

3. Entender el crédito que se contratará:

Antes de firmar, se debe leer detenidamente los términos y condiciones del contrato. Las letras pequeñas son las más peligrosas. Comprender bien las responsabilidades del financiamiento a contratar es crucial para no ser víctimas de engaños y de pagos innecesarios. Hay instituciones financieras que podrán ofrecer tasas de interés del $11 \%$, pero luego informan que la "tasa efectiva" es del $14 \%$, esto sin duda afectará el bolsillo del solicitante.

4. Evaluar la capacidad de pago para nuevas deudas: El presupuesto personal es importante en este punto. Aquí se deberá incluir la cuota de la nueva deuda, para identificar la factibilidad de cubrir el nuevo pago con los ingresos actuales.

Por naturaleza somos consumidores, pero lo importante es darle prioridad al consumo de bienes y servicios que satisfacen necesidades primordiales, además de gustos y deseos. Si se logra lo anterior se ha dado el primer paso de la educación financiera. 